\title{
EXPANSÃO URBANA E DESIGUALDADES SOCIOESPACIAIS EM ITUIUTABA (MG)
}

\section{HÉLIO CARLOS MIRANDA DE OLIVEIRA}

Doutor em Geografia. Docente dos cursos de graduação e pós-graduação em Geografia do Instituto de Ciências Humanas do Pontal, Universidade Federal de Uberlândia ${ }^{1}$

heliocarlos@ufu.br

Resumo: o objetivo deste trabalho se alicerçou na interface entre o teórico e o empírico, buscando entender como as discussões sobre a reestruturação urbana são percebidas na cidade de Ituiutaba (MG), em particular sobre a forma urbana e as diferentes condições socioeconômicas existente na cidade e suas desigualdades socioespaciais.

Palavras-chave: Expansão urbana; Desigualdade socioespacial; Reestruturação urbana; Ituiutaba (MG).

\section{URBAN EXPANSION AND SOCIO-SPACE INEQUALITIES IN ITUIUTABA (MG)}

Abstract: the objective of this work was based on the interface between the theoretical and the empirical, seeking to understand how the discussions about urban restructuring are perceived in the city of Ituiutaba (MG), in particular about the urban form and the different socioeconomic conditions existing in the city and its socio-spatial inequalities.

Keywords: Urban expansion; Socio-spatial inequality; Urban restructuring; Ituiutaba (MG).

\section{EXPANSIÓN URBANA Y DESIGUALDADES SOCIOESPACIALES EN ITUIUTABA (MG)}

Resumen: el objetivo de este trabajo se basó en la interfaz entre lo teórico y lo empírico, buscando comprender cómo se perciben las discusiones sobre la reestructuración urbana en la ciudad de Ituiutaba (MG), en particular sobre la forma urbana y las diferentes condiciones socioeconómicas existentes en la ciudad y sus desigualdades socioespaciales.

Palabras clave: Expansión urbana; Desigualdad socioespacial; Reestructuración urbana; Ituiutaba (MG).

\section{Introdução}

A análise do fato urbano sempre esteve ligada à compreensão do processo de urbanização, que, por sua vez, tem como produto socioespacial a cidade. Para entender a relação cidade- urbanização, deve-se remeter, mesmo que sucintamente, à sua história. Nesse sentido, é necessário enfocar as articulações entre espaço e tempo para depreender o processo de urbanização, principalmente por se tratar de um fenômeno socioespacial fruto da divisão social do trabalho ao modo capitalista de produção.

Sposito (2004) afirma que é preciso realizar esforços analíticos na tentativa de construir uma unicidade espaço $\Leftrightarrow$ tempo da urbanização, rompendo com a tradição positivista que outorga as análises espaciais à Geografia e as temporais à História. Não diferente, Castells (2006) destaca a necessidade da periodização para a compreensão e análise do processo de urbanização, através da associação entre a linearidade do tempo e a sinuosidade dos fatos, considerando, para isso, [...] "a produção das formas espaciais da estrutura social de base" (CASTELLS, 2006, p. 36).

É imprescindível analisar a urbanização como resultado de um processo histórico, pois, como indica Santos (1988), as ações e os objetos geográficos (fixos, sistemas de engenharias, fluxos de relações e conteúdos sociais) são responsáveis pela configuração territorial e pelas paisagens de uma época, de forma que mudanças espaciais raramente eliminam, de uma única vez, as marcas materiais do passado, formando o que o autor denominou de rugosidades do espaço (SANTOS, 2002). Nesse sentido, ele propõe o exame da urbanização do território a partir da empiricização do espaço e do tempo em conjunto, o que

${ }^{1}$ Endereço para correspondência: Rua Vinte, 1600, Tupã. CEP: 38304-402. Ituiutaba-MG, Brasil. 
somente é possível com a periodização da análise. Nas palavras do autor, "É através do significado particular, específico, de cada segmento do tempo, que apreendemos o valor de cada coisa num dado momento" (SANTOS, 1988, p. 83). Ele ainda completa afirmando que "a periodização é indispensável para que, no trabalho de empiricização das categorias, não nos escape o problema de mudança de valor de cada variável segundo os momentos" (SANTOS, 1988, p. 114).

Cabe pontuar que neste trabalho a urbanização é entendida como um processo complexo capaz de conjugar, harmonicamente ou não, a sucessão e o descompasso, a sincronia e a arritima, gerando o fato concreto da urbanização, o produto material, a cidade. Nesse sentido, Castells (2006) propõe que a urbanização seja entendida como um processo que se refere tanto à criação de formas espaciais, principalmente em função da concentração de atividades e pessoas em um único espaço, quanto à presença e difusão de uma cultura formada por hábitos e costumes característicos da vida urbana. A urbanização torna-se, então, a produção social de formas espaciais, que, segundo Castells (2006, p. 47),

[...] refere-se ao processo pelo qual uma proporção significativamente importante da população de uma sociedade concentra-se sobre um certo espaço, onde se constituem aglomerados funcionais e socialmente dependentes do ponto de vista interno, e numa relação de articulação hierarquizada (rede urbana).

Diante do exposto, entender o processo de urbanização e as dinâmicas urbanas de uma parte do território brasileiro é foco deste trabalho. Para isso, propõe-se como objetivo geral investigar o processo de urbanização da cidade de Ituiutaba (MG) a partir da análise das desigualdades socioespaciais e a expansão da cidade resultante da atuação dos agentes econômicos responsáveis pela reestruturação urbana da parte oeste do Triângulo Mineiro na última década do século XX e primeira do século XXI. Nesse sentido, a hipótese deste trabalho é que a expansão da cidade de Ituiutaba (MG), principal centro urbano da parte oeste do Triângulo Mineiro, é oriunda da influência dos agentes econômicos responsáveis pela reestruturação urbana desta região e está acompanhada da intensificação das desigualdades socioespaciais, principalmente na periferia que da cidade, incluindo áreas com significativa valorização imobiliária.

Para alcançar o objetivo proposto este trabalho se alicerçou na interface entre o teórico e o empírico, buscando entender como as discussões apontadas por Soja (1993) e de Sposito $(2004,2007,2007$ a) sobre a reestruturação urbana são percebidas na cidade de Ituiutaba (MG), em particular sobre a forma urbana e as diferentes condições socioeconômicas existente na cidade e suas desigualdades socioespaciais. Nesse sentido, os procedimentos metodológicos se organizam em duas etapas, uma referente à expansão da cidade e sua forma urbana e outra referente aos indicadores de desigualdade socioespacial:

i) Sobre a forma urbana e expansão da cidade foram adotados os seguintes procedimentos metodológicos: a) levantamento de documentos oficiais referentes às leis de criação dos bairros da cidade; b) pesquisa de campo para tipificação dos bairros da cidade em loteamentos ou conjuntos habitacionais; c) elaboração do mapa de expansão urbana por décadas; d) identificação dos agentes responsáveis pela produção espacial das novas formas da cidade; e) análise da morfologia urbana.

ii) Sobre as desigualdades socioespaciais foram adotados os seguintes procedimentos metodológicos: a) eleição dos indicadores disponíveis nos Dados Agregados por Setor Censitário do IBGE (2000-2010) para mensuração das desigualdades socioespaciais: renda, condição de moradia, tipos de moradias, escolaridade; b) levantamento de dados primários em campo sobre as condições socioeconômica-espacial da cidade; c) levantamento de dados do 
Cadastro Nacional dos Endereços para Fins Estatísticos (CNEFE) do IBGE (2010); d) tratamento dos dados e cálculo das classes (frequência) para o total da cidade; e) elaboração dos mapas, por indicadores, para a cidade; f) análise das desigualdades socioespaciais e sua relação com a forma urbana.

A seguir, as análises dos resultados da pesquisa.

\section{Expansão urbana e desigualdades socioespaciais em Ituiutaba (MG): análise dos resultados}

O espaço geográfico de Ituiutaba (MG) foi reelaborado ao longo do tempo para atender as demandas sociais de produção e reprodução da vida humana e do capital a partir da evolução da economia e da sociedade. Nesta cidade, as exigências impostas pela produção agropecuária foram as responsáveis pelas dinâmicas espaciais e pelos processos urbanos recentes, uma vez que possibilitaram mudanças na estrutura técnica produtiva, nas atividades econômicas predominantes e na organização espacial do centro urbano (OLIVEIRA, 2013).

O primeiro indicador desta transformação é o quantitativo populacional da cidade, o qual revela que a partir de meados da década de 1970 a população passou a se concentrar mais nas cidades do que no campo, como ocorreu em todo o restante do território brasileiro. Ituiutaba (MG) é um município que obteve taxas de crescimento positivas no período de 1950 a 2010 (ver Tabela 01), mesmo com as fragmentações territoriais e a diminuição da população do campo em virtude da modernização agrícola. Somente entre 1940 e 1950 houve crescimento da população rural, impulsionado pelas lavouras de arroz, como destacado por Silva (1997), Oliveira (2003), Mateus (2013). Entretanto, a partir da decadência dessa atividade agrícola, a maioria absoluta dos migrantes estabeleceu moradia definitiva na cidade de Ituiutaba (MG), o que resultou em transformações no espaço e nas dinâmicas das cidades (OLIVEIRA, 2013).

Tabela o1 - Ituiutaba(MG): população rural, urbana e total (1940-2010)

\begin{tabular}{ccccccccc}
\hline \multirow{2}{*}{ Situação } & \multicolumn{8}{c}{ Ano } \\
\cline { 2 - 9 } & $\mathbf{1 9 4 0}$ & $\mathbf{1 9 5 0}$ & $\mathbf{1 9 6 0}$ & $\mathbf{1 9 7 0}$ & $\mathbf{1 9 8 0}$ & $\mathbf{1 9 9 1}$ & $\mathbf{2 0 0 0}$ & $\mathbf{2 0 1 0}$ \\
\hline Rural & 30.696 & 48.065 & 42.452 & 17.635 & 9.107 & 6.372 & 5.238 & 4.046 \\
Urbana & 4.356 & 4.407 & 28.254 & 47.021 & 65.133 & 78.205 & 83.853 & 93.125 \\
Total & 35.052 & 52.472 & 70.706 & 64.656 & 74.240 & 84.577 & 89.091 & 97.171 \\
\hline
\end{tabular}

Fonte: adaptado de Oliveira (2013).

Silva (1997) aponta que o crescimento populacional deu-se, em sua maioria, devido a migração de nordestinos para Ituiutaba (MG), buscando melhores condições de vida através do trabalho nas lavouras de arroz.

Nas décadas de 1950 e 1960, os trabalhadores nordestinos chegaram em massa, à procura das novas e promissoras oportunidades que haviam sido anunciadas. Espalharam-se por essa vasta região trazendo seu modo de vida sua linguagem, estabelecendo diferenças, que deram origem a interpretações variadas, gerando explicações, conceitos e preconceitos. (SILVA, 1997, p. o8).

Silva (1997) ainda completa, afirmando que:

O fluxo entre esses dois locais tornou-se cada vez mais intenso. Os nordestinos chegaram e, muitas matas e invernadas foram transformadas 
em lavoura mediante o seu trabalho. Não importa em que condições vieram; todos, incondicionalmente, apostavam as suas fichas no trabalho que ia leválos à prosperidade. A paisagem foi aos poucos sendo transformada e a população do campo vertiginosamente aumentada. (SILVA, 1997, p. 36).

A significativa migração campo-cidade é explicada por Martine (1990) como sendo resultado do processo de territorialização do capital no campo, que expulsou a mão de obra em função da mecanização e provocou forte êxodo rural, além de aumentar o assalariamento da força de trabalho agrícola, com a população residindo nas cidades. A partir da década de 1970 o processo de urbanização mostrou uma face qualitativamente diferente, já que, pela primeira vez na história moderna do país, as áreas rurais tiveram redução absoluta da população e houve crescimento de algumas cidades, seja territorialmente, seja em número de habitantes. Diante disso, é possível afirmar que o processo de urbanização em Ituiutaba (MG) foi redimensionado pelos investimentos da modernização agrícola, tendo como marco temporal a década de 1970, momento em que ocorreu a inversão do local predominante de residência da população.

O efeito do fluxo populacional deu-se sobre a organização do espaço urbano da cidade. Até o fim da década de 1970 ela possuía 31 bairros e loteamentos. O período de maior crescimento da população urbana (década de 1950) foi também o de maior expansão do tecido urbano em uma única década, totalizando 18 bairros (loteamentos e conjuntos habitacionais), conforme destaca o Mapa 01. Vale destacar que, no Brasil, o crescimento físico das cidades vem acompanhado do aprofundamento das desigualdades socioespaciais, conforme destacado por Melazzo (2006).

Mapa o1 - Ituiutaba (MG): expansão urbana (1901-2013)

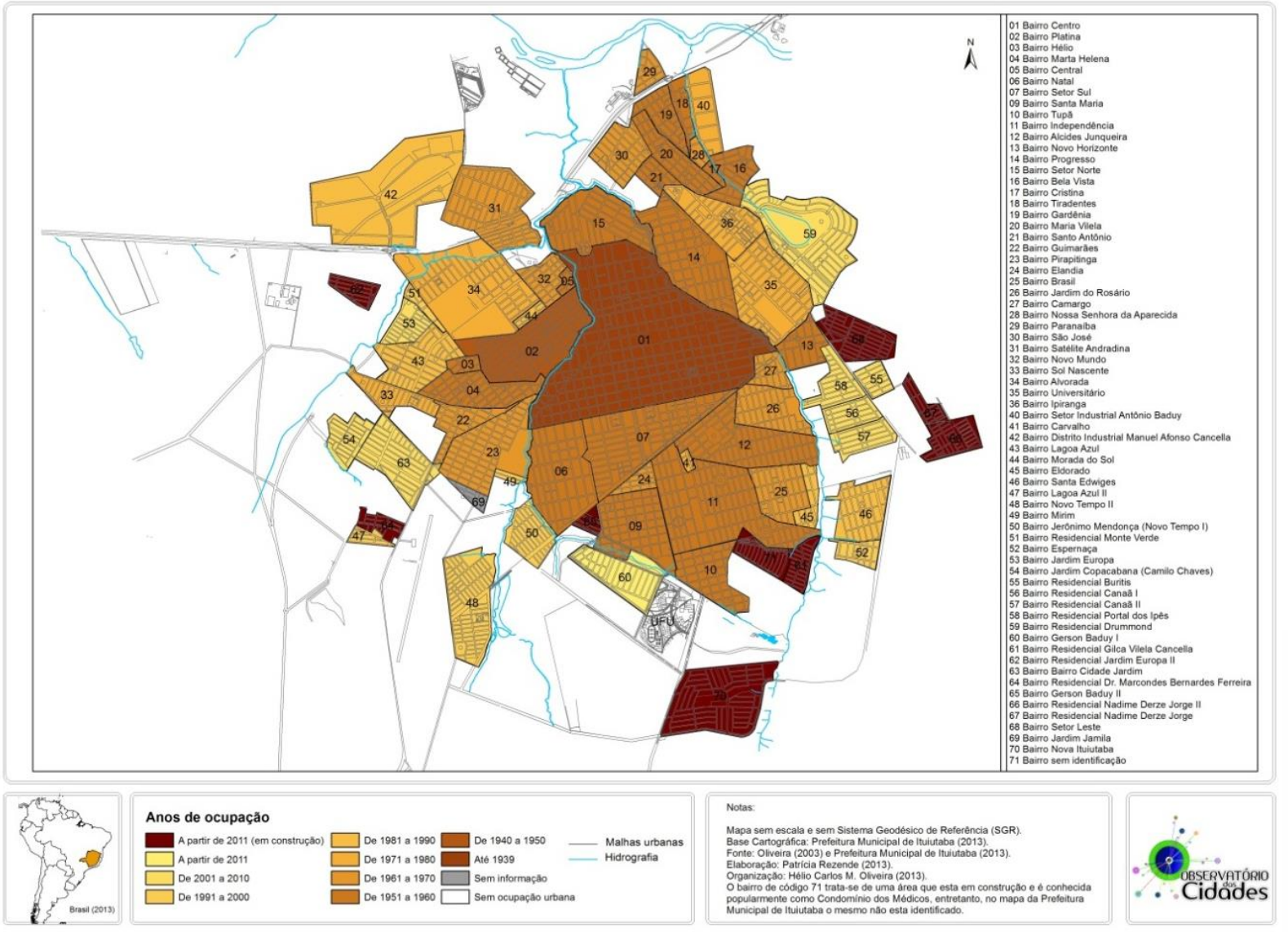

Fonte: Oliveira (2013).

Hélio Carlos Miranda de Oliveira. Expansão urbana e desigualdades socioespaciais em Ituiutaba (MG) Brazilian Geographical Journal: Geosciences and Humanities research medium, Ituiutaba, v. 11, n. 1, p. 97-112, jan./jul. 2020 Página $\mid 100$ 
Até o ano de 1970 a cidade era composta por 29 bairros (loteamentos) e dois conjuntos habitacionais, sendo estes formados, no total, por 370 casas (OLIVEIRA, 2003). Apesar da maior expansão urbana ter acontecido na década de 1950, neste período surgiu somente um conjunto habitacional, o Bairro Natal (1957), com 70 unidades residenciais. Exatos dez anos após a construção do primeiro conjunto habitacional, surgiu o Bairro Ipiranga, com 300 casas.

Estas informações indicam a inexistência de preocupação com a política habitacional no município. Até a década de 1970 o poder público municipal de Ituiutaba (MG) se caracterizava como o principal agente produtor do espaço, muito mais pela sua atuação na organização espacial da cidade - oferecimento de infraestruturas e serviços -, do que por possuir políticas que incentivassem a construção de moradias. Nesse sentido, Rodrigues (2003, p. 20) afirma que o Estado [...] "tem presença marcante na produção, distribuição e gestão dos equipamentos de consumo coletivo necessários à vida nas cidades" [...], destacando, entre eles, a rede de infraestruturas (abastecimento de água, sistema de coleta de esgoto, energia elétrica, iluminação pública, telefonia), o sistema viário, o transporte coletivo, os serviços de saúde e educação, os espaços livres, verdes e de lazer, além da construção de habitações para a população mais pobre da cidade.

Este cenário começa a ser alterado a partir da década de 1970, com a construção de 860 casas em seis conjuntos habitacionais, erigidos em nove etapas diferentes ${ }^{2}$. Entretanto, estavam muito aquém das necessidades habitacionais da época, uma vez que no período de 1970-1980 a população urbana cresceu $38,52 \%$, passando de 47.021 para 65.133 habitantes, o que equivalia a 21,06 habitantes por casa construída em conjunto habitacional. Nos anos anteriores a relação de habitantes por moradia construída era muito maior: 403,62 entre 1950-1960 e 62,55 no período de 1960-1970 (OLIVEIRA, 2013). Esse desequilíbrio acentuou os problemas sociais da cidade, como indicado por Oliveira (2003, p. 121):

O desemprego rural [migração campo-cidade] também foi causa/consequência do desemprego urbano. [...] a cidade viu crescer suas áreas periféricas, sem poder oferecer, em curto prazo, as infraestruturas necessárias.

Outro período que chama atenção na expansão urbana de Ituiutaba (MG) é o iniciado na década de 2000, quando dez conjuntos habitacionais foram construídos entre 2001 e 2010, totalizando 2.895 habitações, todas financiadas por programas habitacionais públicos (estadual ou federal), entre eles, o Minha Casa Minha Vida ${ }^{3}$. Já a partir de 2011, foi iniciada a construção de nove novos bairros, dos quais dois são loteamentos, contendo aproximadamente 1.200 lotes e sete conjuntos habitacionais com cerca de 4.820 unidades residenciais. Os investimentos do Programa Minha Casa Minha Vida dinamizaram o mercado imobiliário da cidade, tanto pela comercialização de terras urbanas e de materiais para a construção dos imóveis, quanto pela contratação de mão de obra e serviços e pela busca por financiamentos. (OLIVEIRA, 2013).

Os dados do Cadastro Nacional dos Endereços para Fins Estatísticos (CNEFE) do IBGE (2010) possibilitaram elaborar de mapas que apresentam o percentual de edificações em construção no total de endereços urbanos, sendo que em Ituiutaba (MG), as áreas (Mapa 02) com os dois maiores percentuais de edificações (de $0,227 \%$ a $2,474 \%$ e de $0,815 \%$ a 2,475\%) correspondiam aos conjuntos habitacionais cujas construções se iniciaram em 2010, na zona sudeste da cidade; e havia ainda três loteamentos (0,071\% a 0,226\%), dos quais dois foram influenciados diretamente pela instalação do campus da Universidade Federal de Uberlândia (UFU) na zona sul da cidade e o terceiro, pela construção de condomínio fechado

2 O financiamento e a produção de empreendimentos imobiliários nas décadas de 1970 e 1980 realizados pelo Banco Nacional de Habitação (BNH). A respeito da atuação do BNH, confira: Soares (1988).

${ }^{3}$ A respeito do Programa Minha Casa Minha Vida (PMCMV), confira: Cardoso (2013). 
na zona nordeste (Mapa 02). É importante destacar que a comercialização dos lotes no condomínio e no loteamento do entorno é anterior à instalação do campus da UFU; entretanto, em virtude das ações dos agentes produtores do espaço urbano, a zona sul da cidade de Ituiutaba (MG) foi a que teve maior valorização das terras, além de ser o novo eixo de expansão da cidade (OLIVEIRA, 2013).

Mapa 02 - Ituiutaba (MG):

\% de edificações em construção no total de endereços urbanos (2010)

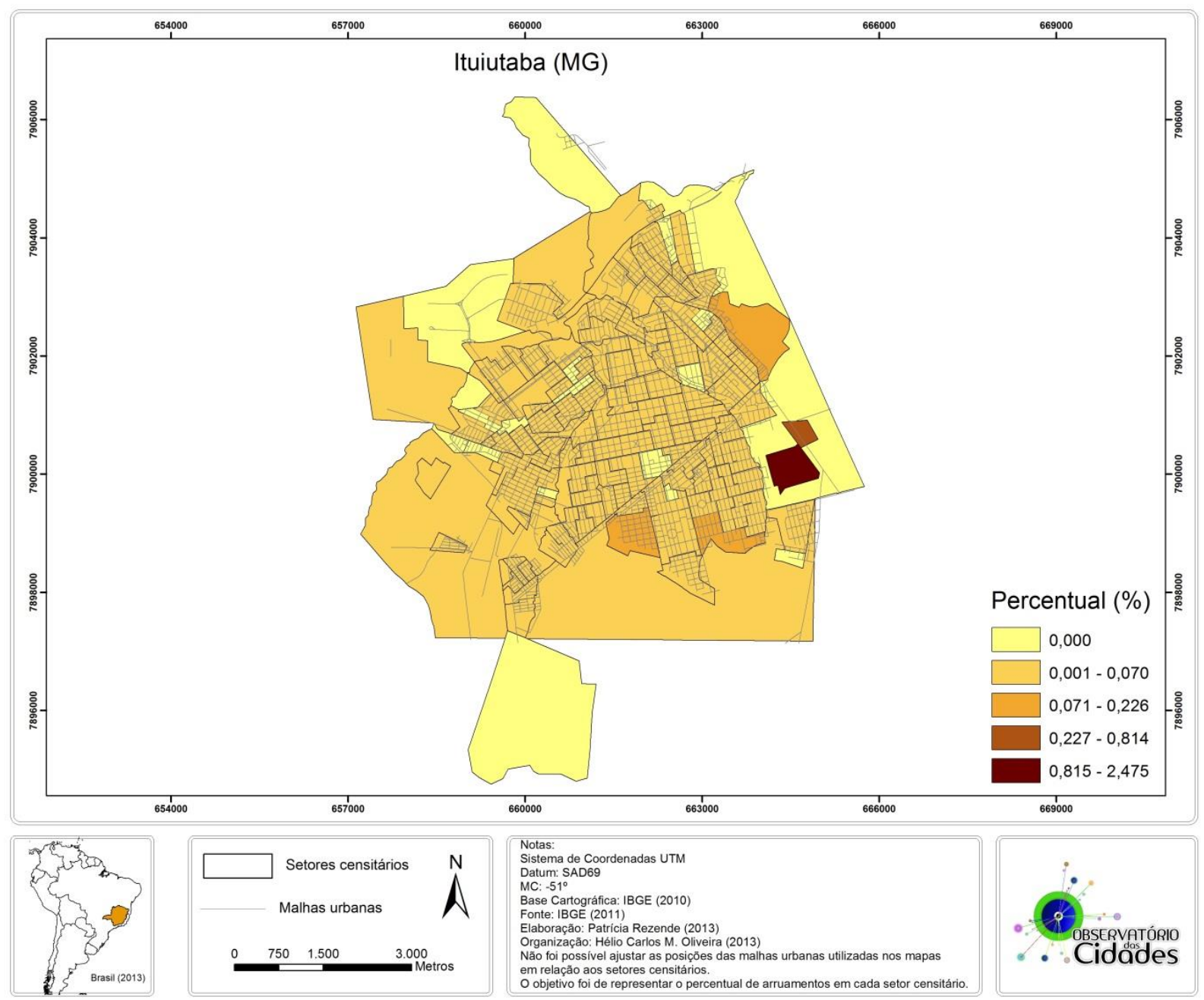

Fonte: Oliveira (2013).

A análise dos mapas 01 e 02 permite concluir que os papéis desempenhados pelos atores responsáveis pela produção do espaço urbano da cidade de Ituiutaba (MG) reestruturam a cidade, impulsionados pelas transformações na economia regional, ou seja, pela reestruturação urbana, de forma semelhante ao apontado nos estudos de Soja (1993) e de Sposito (2004, 2007, 2007a). A reestruturação urbana na região que está localizada a cidade de Ituiutaba (MG) (parte oeste do Triângulo Mineiro) está ligada ao desenvolvimento das atividades agrícolas, sendo que Ituiutaba (MG) foi a única cidade capas de congregar estabelecimentos relacionados tanto ao consumo produtivo quanto ao consumo consumptivo, tornando-se, assim, o principal centro urbano da região (OLIVEIRA, 2013).

O impacto das atividades agrícolas sobre a estrutura da cidade resultou na expansão urbana, tanto por conjuntos habitacionais quanto por loteamentos, de acordo com o indicado nos mapas 01 e 02. A necessidade de construção de moradias na cidade sempre esteve ligada 
à migração de mão de obra de população agrícola, ou seja, de pessoas que residem na cidade e exercem atividade laboral no campo, principalmente para o corte de cana-de- açúcar, a fim de atender a produção das usinas ligados ao setor agroindustrial canavieiro da região.

Fonseca e Santos (2011) ao estudarem a relação cidade-campo em Ituiutaba (MG), apontaram que a instalação de usinas sucroalcooleiras na região veio acompanhada da migração de trabalhadores - a maioria, nordestinos em busca de melhores salários e qualidade de vida - e dos problemas sociais oriundos da atividade, tais como: a expulsão dos pequenos proprietários do campo e a concentração de terras entre latifundiários que se ocupavam do plantio da monocultura da cana-de-açúcar; as sobrecargas nos serviços de saúde e educação das cidades; o aumento dos preços de aluguéis e imóveis, em virtude do crescimento da demanda. Por outro lado, o acréscimo populacional induziu o desenvolvimento da economia urbana, principalmente no setor terciário, em decorrência das necessidades dos "novos" consumidores (OLIVEIRA, 2013).

O déficit habitacional em Ituiutaba (MG), destacado na Tabela 02, indica a demanda por habitações no período de 2007 a 2011, o que explica o significativo crescimento no número de conjuntos habitacionais na cidade a partir da criação do Programa Minha Casa Minha Vida, visto que a cidade concentra 74,53\% do déficit habitacional de sua microrregião geográfica. Em contrapartida, é também a cidade com maior número de construção de novos bairros a partir de 2011, que somam nove, dos quais sete são conjuntos habitacionais e dois loteamentos, como já indicado no Mapa 01.

Tabela 02 - Ituiutaba (MG): estimativas do déficit habitacional (2007-2011)

\begin{tabular}{cccc}
\hline Município e MRG & Déficit habitacional & $\begin{array}{c}\text { \% no total de } \\
\text { habitações }\end{array}$ & $\begin{array}{c}\text { Número de } \\
\text { domicílios }\end{array}$ \\
\hline Ituiutaba & 3.402 & 10,40 & 32.707 \\
Microrregião & 4.564 & 9,42 & 48.427 \\
\hline
\end{tabular}

Fonte: adaptado de Oliveira (2013).

Enquanto as demandas por moradia não são atendidas, o mercado de aluguéis na cidade torna-se altamente rentável para os donos dos imóveis, mas extremamente prejudicial para aqueles que são obrigados a viver sob essa condição. Ituiutaba (MG) possui a taxa de 4,51\% do total de domicílios particulares permanentes urbanos de cedente de aluguel; o total de imóveis alugados corresponde a 43,37\% do déficit habitacional municipal.

A transformação no mercado imobiliário da cidade foi predominantemente resultado da migração de trabalhadores ligados ao setor agroindustrial canavieiro, no entanto, a instalação do campus da UFU na zona sul da cidade de Ituiutaba (MG) contribuiu, sobremaneira, para a dinamização das demandas imobiliárias recentes, uma vez que servidores e estudantes, oriundos de cidades distantes de Ituiutaba (MG), buscaram no aluguel a opção inicial para moradia na cidade.

O Mapa 03 representa a proporção de domicílios alugados no total de domicílios particulares permanentes de Ituiutaba (MG), nos anos de 2000 e 2010; indica também a concentração de aluguéis no centro da cidade, como tradicionalmente acontece em todas as cidades. No ano de 2010, os domicílios alugados concentraram-se em dois setores próximos aos campi das instituições de ensino superior: na zona sul, próximo à UFU, e na zona leste, próximo à UEMG e à Faculdade FacMAis.

A aquisição de moradias deu-se principalmente nas áreas periféricas, sendo que, em Ituiutaba (MG), esse processo foi impulsionado tanto pela construção de conjuntos habitacionais ou abertura de loteamentos, quanto pela valorização das áreas que sofreram influência direta da instalação da UFU, na zona sul, e do condomínio fechado, na zona leste (Mapa 04).

Os novos conjuntos habitacionais surgiram em áreas que já apresentavam problemas ligados à habitação, como aqueles referentes às condições de moradia e infraestrutura. A grande concentração de logradouros sem pavimentação é um dos problemas recorrente na 
cidade, uma vez que era prática comum do poder legislativo municipal aprovar loteamentos ou conjuntos habitacionais sem a infraestrutura básica4. $\mathrm{O}$ mapa 05 indica as áreas da cidade com maior percentual de domicílios particulares permanentes sem pavimentação no logradouro.

Mapa 03 - Ituiutaba (MG): \% de domicílios alugados no total de domicílios urbanos particulares permanentes da cidade (2000-2010)

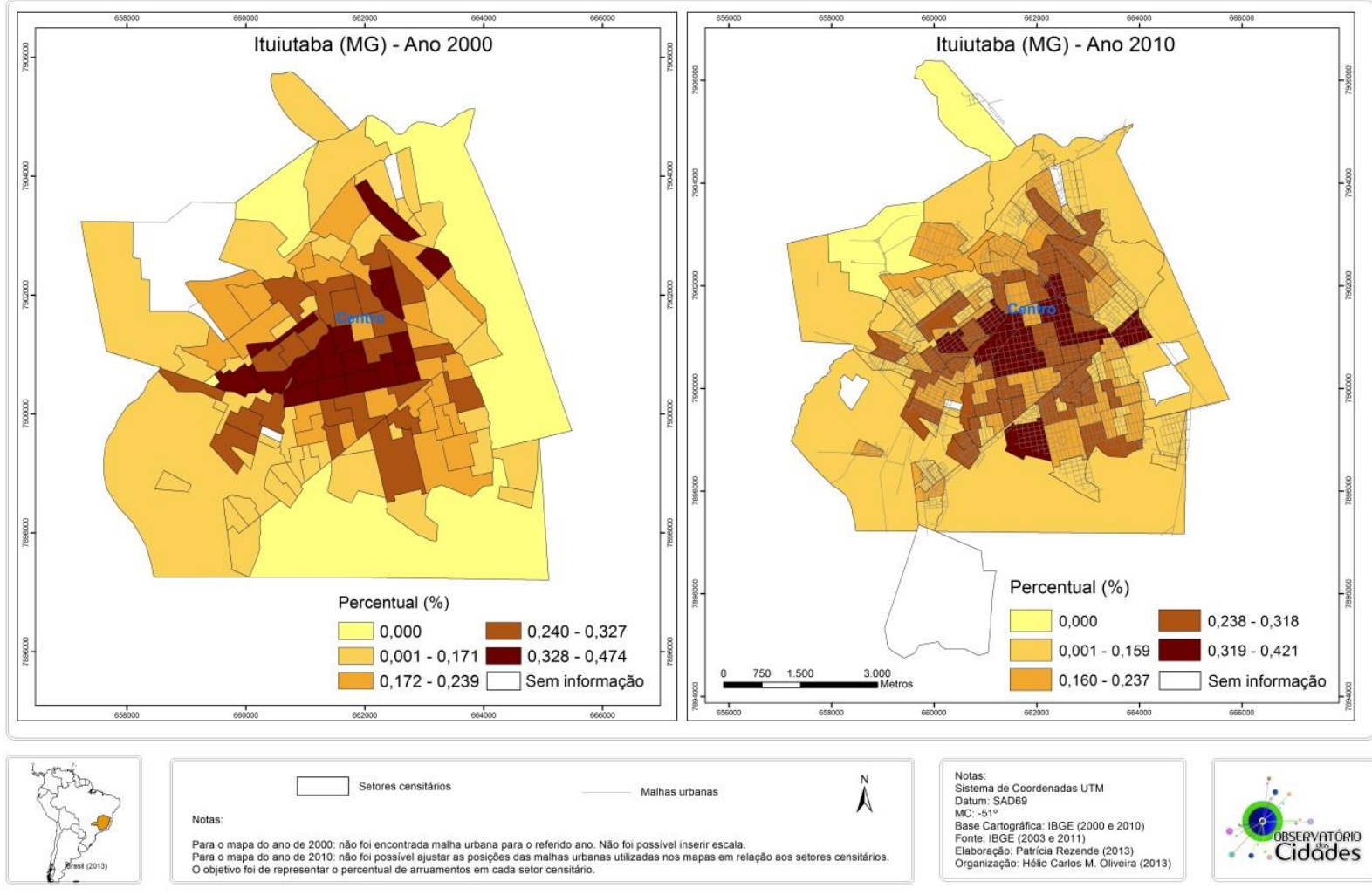

Fonte: Oliveira (2013).

A representação do Mapa o5 permite inferir que esta era uma área com pequena valorização imobiliária até o anúncio da implantação e construção do campus da UFU na cidade, que aconteceu em 2006. Segundo relatos de moradores dos bairros do entorno da UFU, até o ano de 2006 era possível adquirir terrenos de 360 metros quadrados por um preço médio de $\mathrm{R} \$ 2.500,00$; no ano de 2013, esses valores atingiram média de $\mathrm{R} \$$ 60.000,00, com alguns terrenos avaliados em mais de $\mathrm{R} \$ 100.000,00^{5}$, dependendo da sua localização. Antes da chegada da UFU à Ituiutaba, a área mais prestigiada da cidade quanto ao aspecto imobiliário era a zona leste que, em virtude da instalação do condomínio fechado, direcionava a expansão para aquela parte da cidade. O percentual de domicílios com logradouros sem pavimentação era pequeno, se comparado com a zona sul, o que indicava a presença de infraestruturas urbanas (OLIVEIRA, 2013).

Analisar a condição de moradia ajuda a compreender o processo de produção do espaço urbano de Ituiutaba, pois a presença de habitações semiadequadas ou inadequadas evidencia as desigualdades espaciais existentes e expressam as condições socioambientais das áreas. A concentração de moradias em condição semiadequada ou inadequada na

4 Essa prática aconteceu no período anterior à aprovação do Estatuto da Cidade (lei federal 10.257, de 10 de julho de 2001) que regulamenta os artigos 182 e 183 da Constituição Federal, estabelece diretrizes gerais da política urbana e dá outras providências. Para mais detalhes sobre a lei acesse: http://www.planalto.gov.br/ccivil 03/leis/leis 2001/l10257.htm

5 Valor do dólar em janeiro de 2013: $\mathrm{R} \$ 2,06$. 
periferias da cidade revela que há uma tendência do processo de urbanização agrupar populações mais pobres em áreas pouco privilegiadas por infraestruturas, ambientalmente frágeis e socialmente excluídas.

Mapa 04 - Ituiutaba (MG): \% de domicílios adquiridos no total de domicílios urbanos particulares permanentes da cidade (2000-2010)

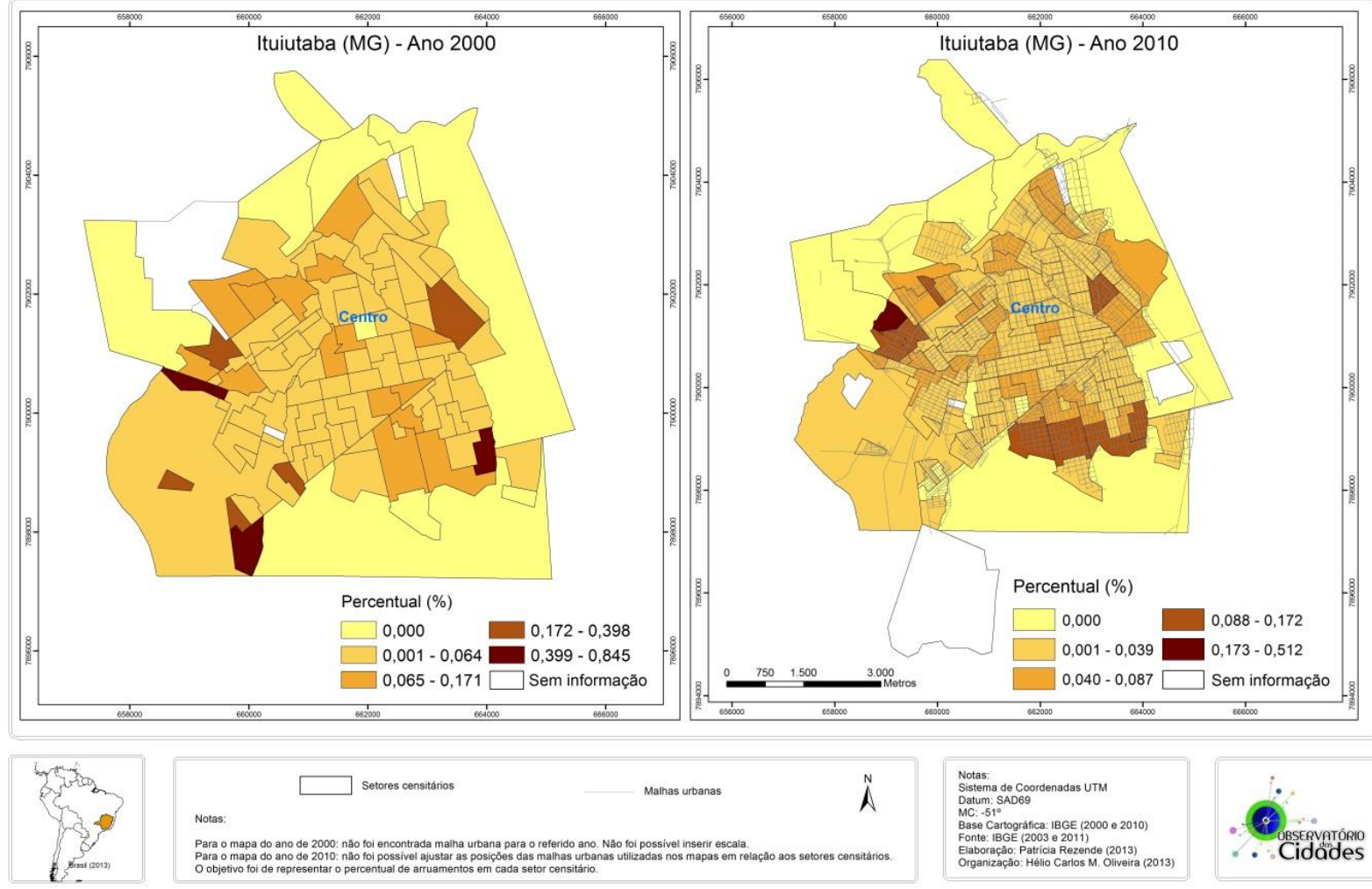

Fonte: Oliveira (2013).

Na cidade de Ituiutaba (MG) a lógica espacial da existência dessas moradias está relacionada à presença de infraestruturas urbanas nos bairros e às condições socioeconômicas da população (Mapa 06), ou seja, nos bairros com as condições urbanas e econômicas mais precárias é que se concentram as moradias semiadequadas ou inadequadas à habitação humana.

Nas zonas norte e nordeste, os bairros que se destacam nesse aspecto foram os criados na década de 1960, com infraestrutura urbana mínima (água encanada, rede de esgoto e iluminação pública), sem pavimentação de vias e calçadas, distantes do centro e segregados do restante do tecido urbano pela rodovia BR-365, que se localiza na parte norte da cidade. Esses bairros foram ocupados por populações que migraram do campo para a cidade à procura de empregos, em decorrência da decadência do arroz e do início da utilização de máquinas na produção agrícola.

Os bairros com maior percentual de moradias semiadequadas ou inadequadas nas zonas sul e sudeste foram criados, respectivamente, nas décadas de 1950 e 1980, visando atender as demandas por habitação dos migrantes que chegavam à cidade para trabalhar nas lavouras da região (na década de 1950) ou oriundos do campo após a expulsão da população em decorrência da modernização agrícola (na década de 1980). 
Mapa 05 - Ituiutaba (MG): \% de domicílios em logradouros sem pavimentação no total do setor censitário (2010)

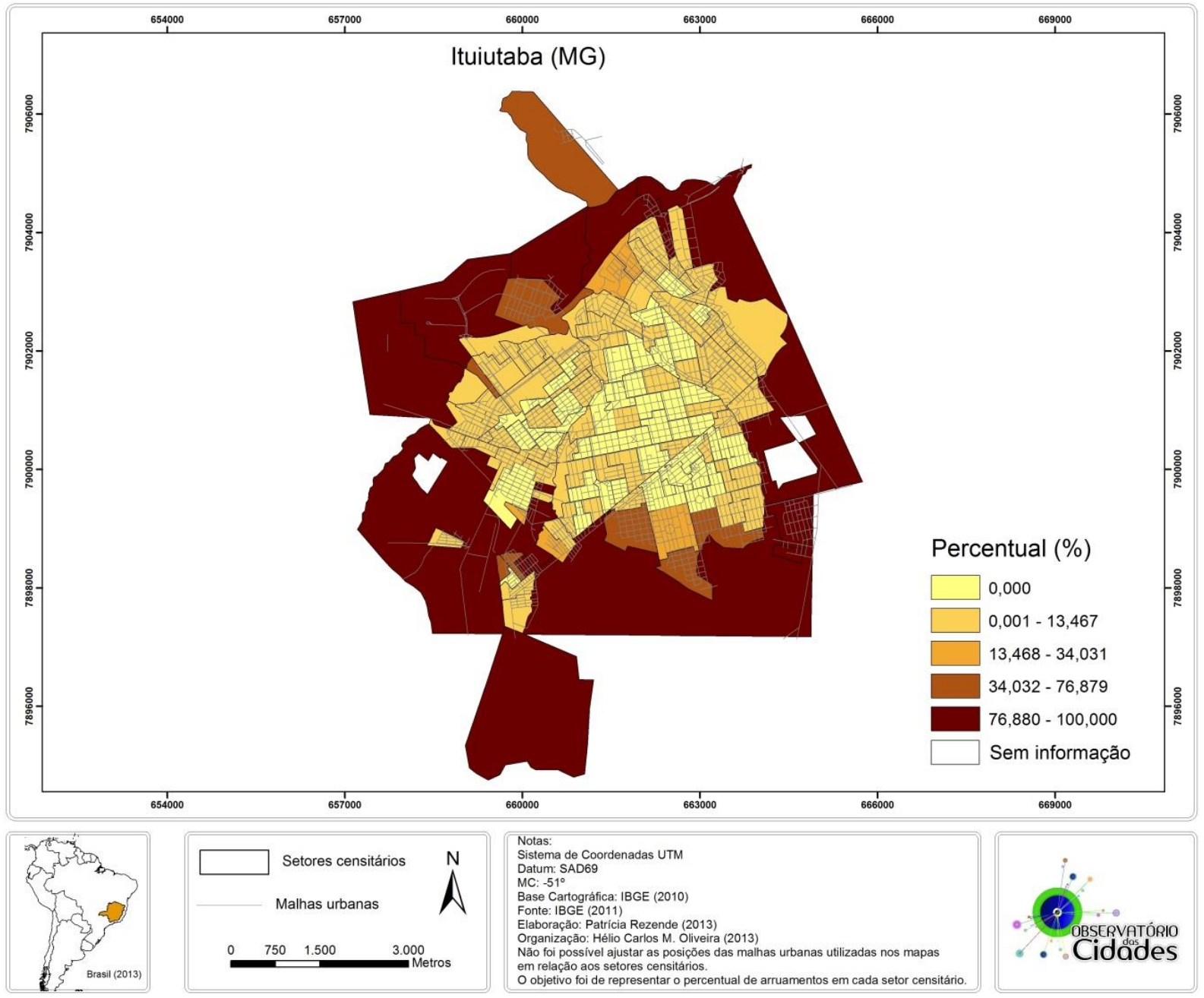

Fonte: Oliveira (2013).

A presença de moradias precárias na área central da cidade de Ituiutaba (MG) se dá em virtude de ainda existirem alguns domicílios particulares desocupados ou ocupados por pessoas de idade elevada, que se instalaram nesses locais em período anterior a 1940, quando essa parte da cidade ainda era periférica. Além disso, a presença de moradores nas margens do córrego Pirapitinga também contribui para elevação desse percentual na área central.

Os bairros com moradias em condições semiadequadas ou inadequadas para a vida humana em todas as cidades da MRG foram criados sob o único argumento da necessidade de prover espaços para construção de domicílios àqueles que não tinham acesso, entretanto, sem se preocupar com o efetivo bem-estar populacional, uma vez que foram edificados em áreas que atualmente ainda apresentam problemas urbanos, como logradouros sem pavimentação, ausência de serviços de educação e saúde (escolas, creches, postos de saúde), transporte público ineficiente e problemas sociais, como a baixa condição econômica da população. Todos estes fatores demonstram que, em determinados períodos das histórias das cidades, não houve preocupação dos poderes públicos municipais em prover áreas qualificadas para moradia. 
Mapa 06 - Ituiutaba (MG): \% de domicílios em condições de moradia semiadequadas ou inadequadas no total do setor censitário (2010)

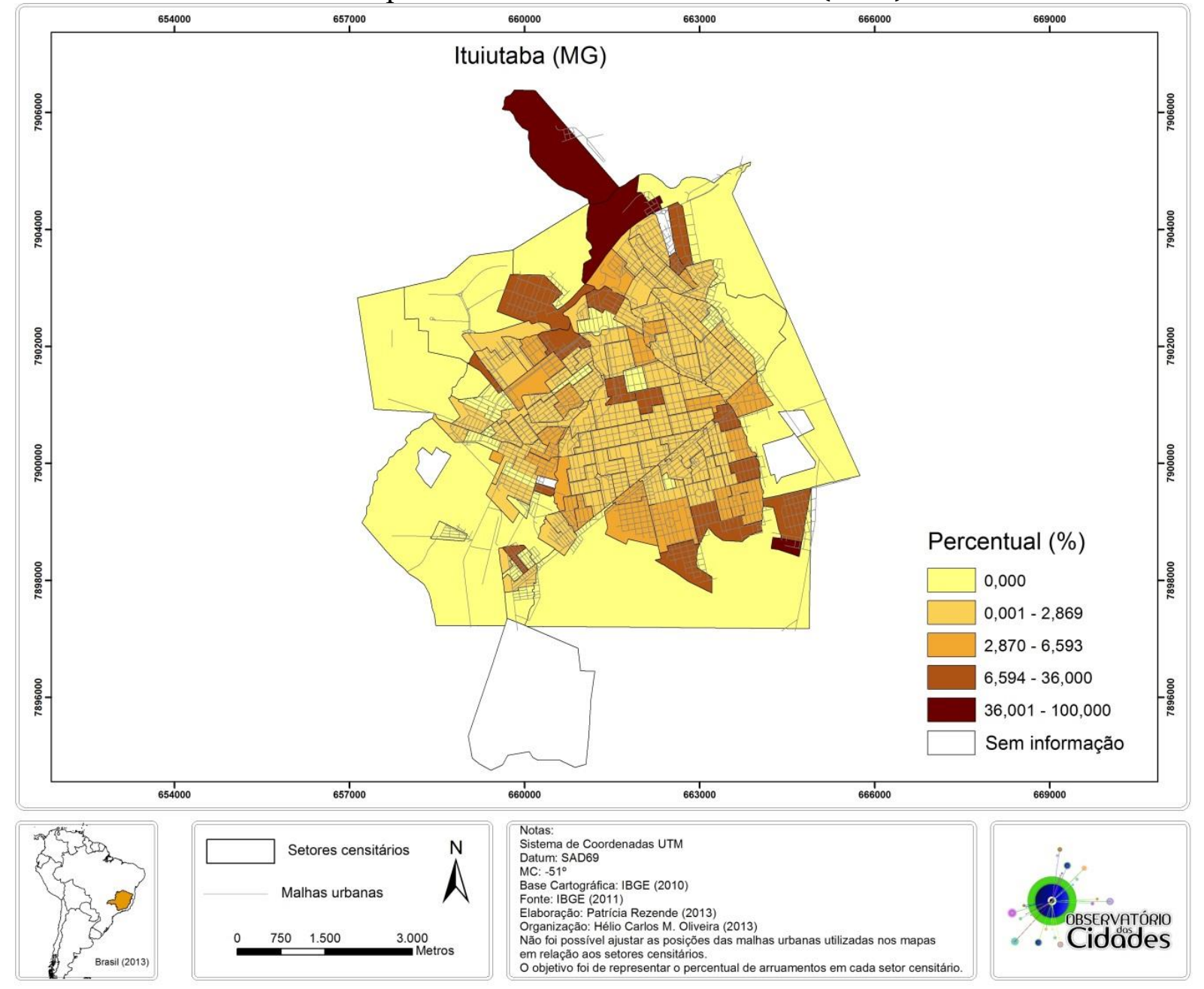

Fonte: Oliveira (2013).

A condição econômica da população é um aspecto que contribui para o entendimento da produção, estruturação e dinamismo do espaço urbano da cidade. Em Ituiutaba (MG), a concentração de chefes de família com rendimento nominal mensal de até um salário mínimo acontece na periferia (Mapa 07). No ano de 2000, essa população ocupava os bairros das zonas oeste, sudoeste, sul e sudeste da cidade, historicamente as áreas mais pobres, formadas por conjuntos habitacionais e loteamentos para populações de baixa renda, a maioria construída sem infraestrutura de pavimentação de ruas e calçadas.

No ano de 2010 essa realidade se transforma, pois, apesar de aumentar o percentual de chefes de família com renda mensal de até um salário mínimo em alguns setores censitários, houve uma redução significativa do número de setores nos percentuais mais altos e aumento daqueles com percentuais mais baixos. Isso indica que a renda da população da cidade aumentou, o que pode ser atribuído a vários fatores, como os programas sociais do governo federal, por exemplo, o Bolsa Família; a oferta de emprego vinculado ao setor agroindustrial canavieiro, principalmente a partir de 2003; a oferta de emprego na construção civil, em virtude dos conjuntos habitacionais, ou no setor terciário da econômica urbana, em decorrência do tímido crescimento a partir de 2003. 
Mapa 07 - Ituiutaba (MG): \% de chefes de família com rendimento nominal mensal de até um salário mínimo no total da cidade (2000-2010)

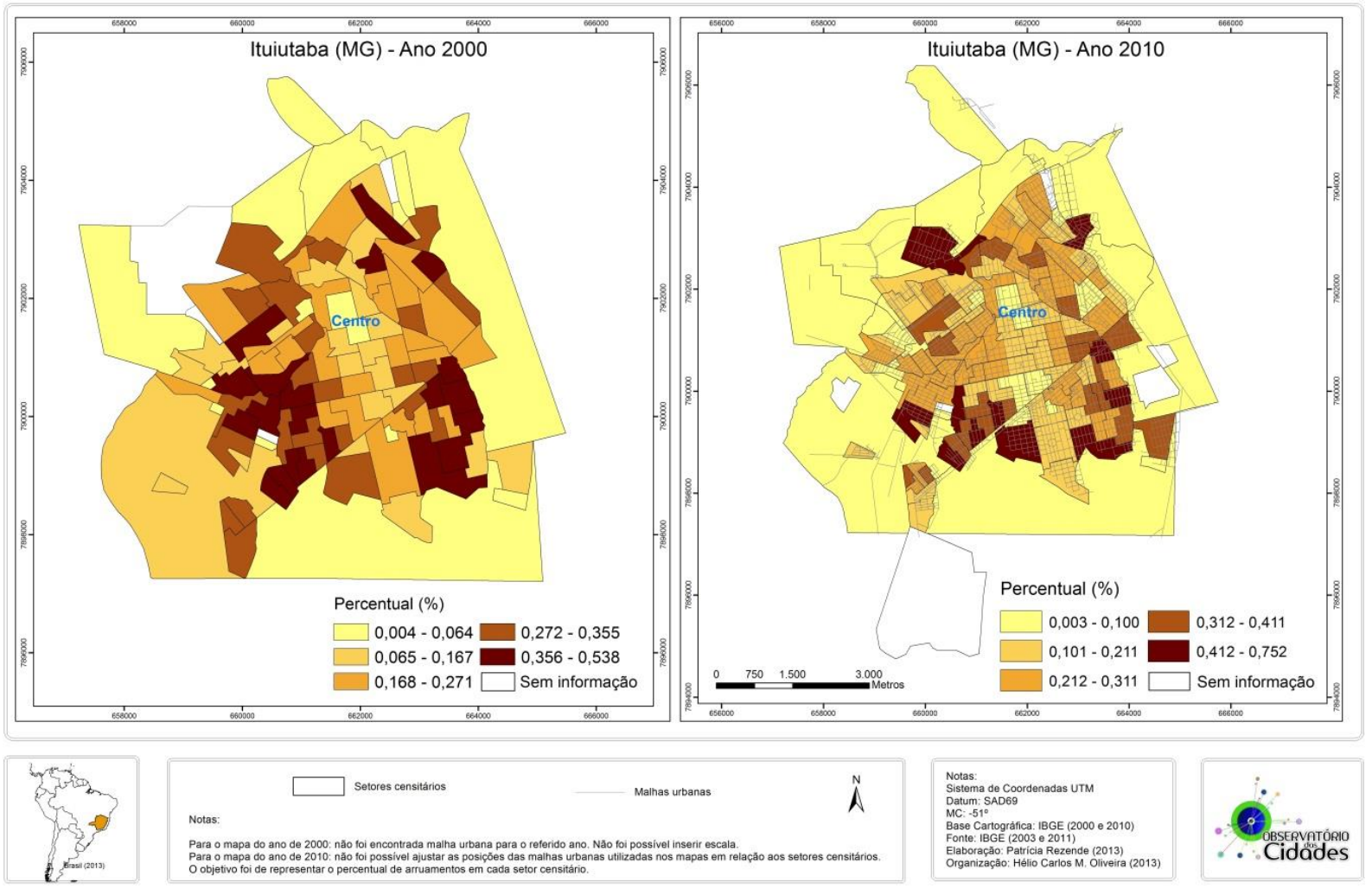

Fonte: Oliveira (2013).

Apesar da redução entre os anos de 2000 e 2010, a concentração dos chefes de família com renda de até um salário mínimo se manteve, em 2010, em bairros da parte sul da cidade e em dois bairros da zona norte.

Em oposição, os chefes de família com rendimento nominal mensal de quinze salários mínimos ou mais ocupam uma faixa de território que tem origem no centro e se estende até a zona sul da cidade (Mapa 08), formada pelos bairros Centro, Setor Sul e Independência, além de um bairro a leste, próximo ao campus da UEMG, chamado Setor Universitário.

O número de setores sem a presença desses chefes de família aumentou no período entre 2000 e 2010, demonstrando que houve concentração de renda na cidade, principalmente naquelas áreas que historicamente foram ocupadas por pessoas de mais alta renda. Além disso, os dados demonstram que existiu redução no percentual de chefes por setor, uma vez que no ano de 2000 o máximo era de $0,53 \%$, passando para $0,12 \%$ em 2010.

Provavelmente os dados do próximo censo, que será realizado em 2020, indicarão concentração de população de alta renda na zona sul da cidade, em detrimento do centro, uma vez que é a área com maior valorização imobiliária nos últimos sete anos, onde há previsão de instalação de equipamentos e infraestrutura que agregarão valores à terra urbana, como um condomínio fechado, loteamentos voltados para a classe média, um pequeno centro comercial e um shopping center, que está em fase de elaboração de projetos6. Esses investimentos serão financiados, em parte, por grupos econômicos locais e por grupos imobiliários de Uberlândia (MG) e da região de Ribeirão Preto (SP) (OLIVEIRA, 2013). 
Mapa 08 - Ituiutaba (MG): \% de chefes de família com rendimento nominal mensal de quinze salários mínimos ou mais no total da cidade (2000-2010)

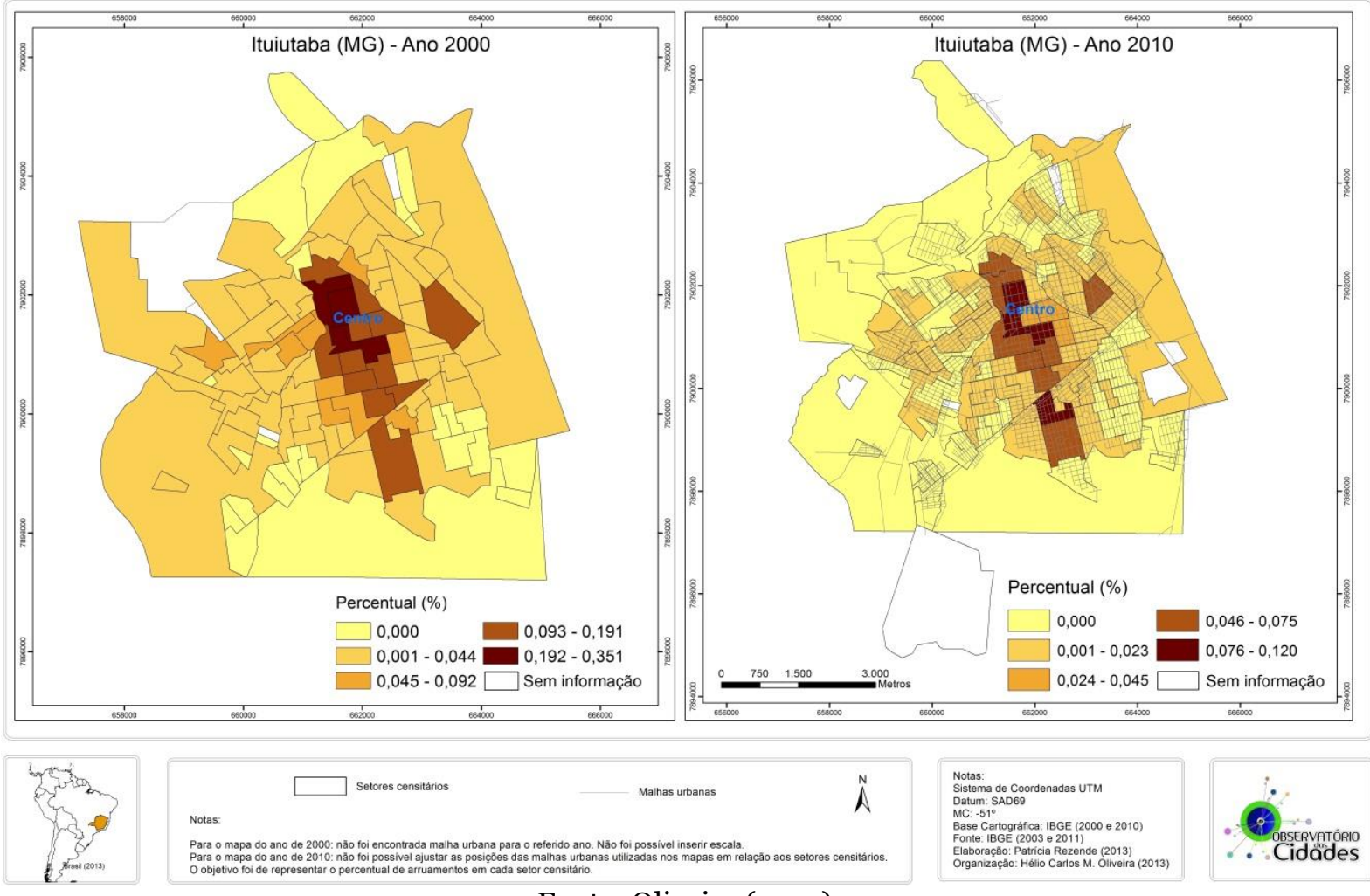

Fonte: Oliveira (2013).

A distribuição espacial dos chefes de família sem rendimento nominal mensal (Mapa o9) é outra informação que chama atenção em Ituiutaba (MG), pois no ano 2000, esses habitantes estavam concentrados nos bairros que formam o anel periférico da cidade e, em 2010, passaram a se concentrar nos bairros das zonas sudoeste e sul. Ao comparar os dados de 2000 com os de 2010, percebe-se que neste último ano houve aumento percentual do número de chefes de família sem rendimento, acompanhado da concentração dessas pessoas na metade sul da cidade.

A análise conjunta dos mapas 07, 08 e 09 permite inferir que, apesar da tendência de valorização imobiliária do setor sul nos últimos sete anos, a cidade ainda não apresenta uma diferenciação espacial (segregação) por zonas, mas sim por bairros. Exemplo desta dinâmica são os bairros da zona sul, onde, em função da instalação do campus da UFU, o preço da terra e dos imóveis aumentou significativamente, atraindo populações de média e alta renda. Ao mesmo tempo, é uma zona da cidade com significativo percentual de moradias semiadequadas ou inadequadas (Mapa 06) e com logradouros sem pavimentação (Mapa 05), indicando que a cidade está passando por uma mudança em sua lógica imobiliária, ou seja, está sofrendo uma reestruturação.

A reestruturação urbana não resultou somente em transformações nas dinâmicas imobiliárias da cidade, mas também na reestruturação do setor terciário da economia, consolidando Ituiutaba (MG) como principal centro urbano da parte oeste do Triângulo Mineiro, tanto no atendimento do consumo produtivo ligado à agropecuária quanto do consumo consumptivo da população. 
Mapa o9 - Ituiutaba (MG): \% de chefes de famílias sem rendimento nominal mensal no total da cidade por setor censitário (2000-2010)

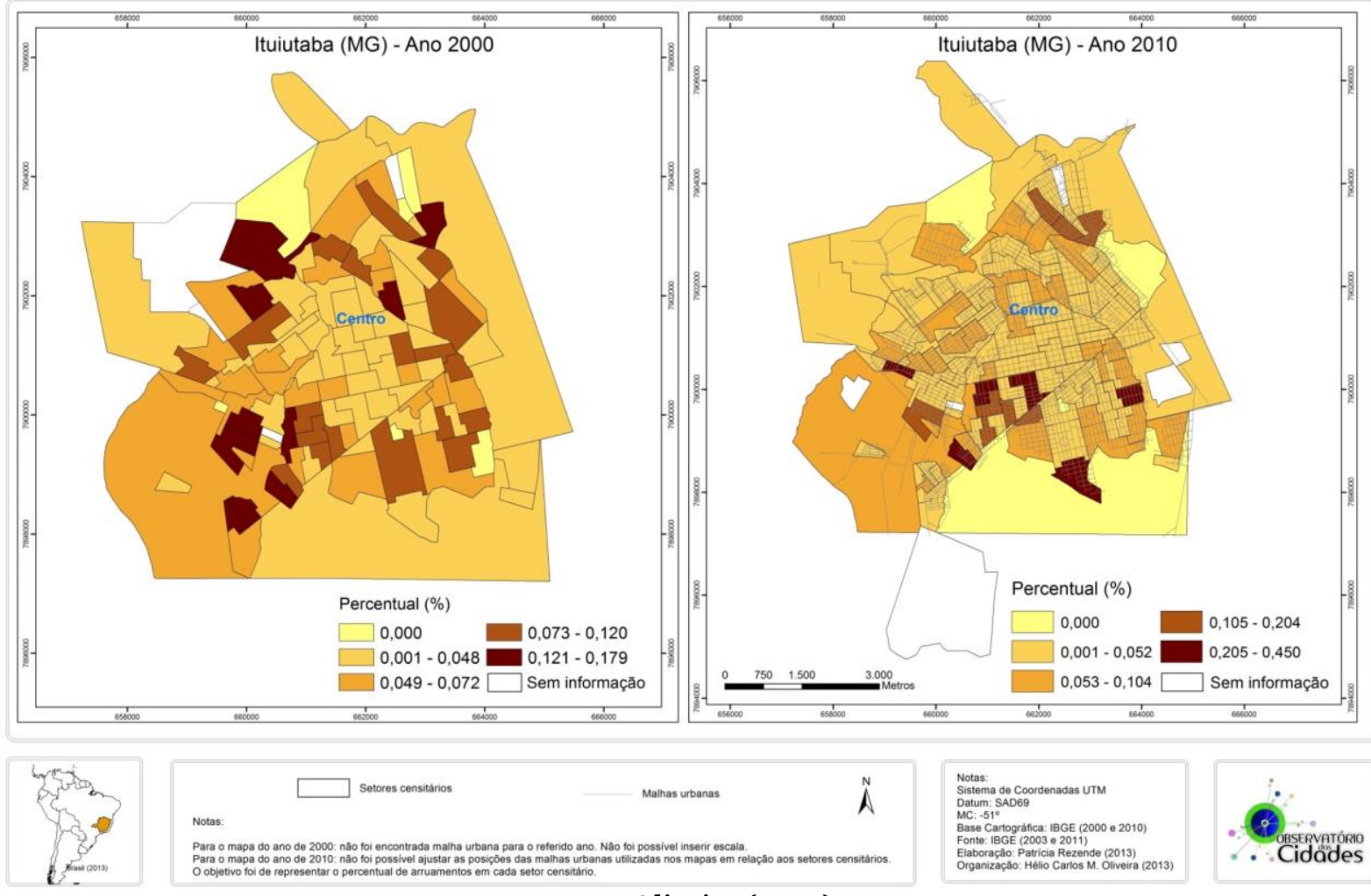

Fonte: Oliveira (2013).

Pode-se afirmar que a modernização agrícola nesta área, desde a década de 1970, a implantação das agroindústrias canavieiras para produção de açúcar e etanol, a migração de mão de obra para trabalhar nas lavouras de cana-de-açúcar, o crescimento das atividades comerciais e as transformações imobiliárias recentes, incentivadas principalmente pela instalação das instituições públicas de ensino, foram responsáveis por dinamizar a economia urbana e modificar as cidades.

Isso acontece por Ituiutaba (MG) consolida-se como polo regional com interações espaciais em diferentes níveis escalares, entre as quais, as nacionais e internacionais estão vinculadas à existência de agroindústrias dos setores de beneficiamento de grãos, laticínio, frigorífico e sucroalcooleiro, com sua produção voltada, principalmente, para as demandas do mercado externo (exportação), no entanto, sem deixar de atender o mercado interno brasileiro. Já na escala regional, os serviços de saúde e educação superior são os responsáveis pela intensificação das interações, acompanhados da comercialização de alguns produtos produzidos nas unidades industriais menores da cidade, como: beneficiadoras de café (torração e moagem), frigoríficos, laticínios e olarias. Da mesma forma, o setor terciário de Ituiutaba (MG) se estabelece como centralizador das relações regionais, atendendo tanto as necessidades de sua população, quanto das cidades vizinhas, o que resulta no aumentado do dinamismo deste setor.

\section{Referências}

CARDOSO, Adauto Lucio (org.). O programa minha casa minha vida e seus efeitos territoriais. Rio de Janeiro: Letra Capital. 2013. 
CASTELLS, Manuel. A questão urbana. $3^{\text {a }}$ edição. Rio de Janeiro: Paz e Terra, 2006.

FONSECA, Rogério Gerolineto; SANTOS, Joelma Cristina dos. A relação cidade-campo no município de Ituiutaba (MG). Horizonte Científico, Uberlândia, v. 5, p. 1-29, 2011.

MARTINE, George. Fases e faces da modernização agrícola brasileira. Planejamento e Políticas Públicas, Brasília, v.1, n.1, p.3-44, jun. 1990.

MATEUS, Renato. A dinâmica da agricultura no cerrado: do apogeu do arroz à modernização do campo na região de Ituiutaba (MG) - 1946-1974. 2013. 84f. Monografia (Bacharelado em História) - Faculdade de Ciências Integradas do Pontal, Universidade Federal de Uberlândia, Ituiutaba, 2013.

MELAZZO, Everaldo Santos. Padrões de desigualdade em cidades paulistas de porte médio: a agenda das políticas públicas em disputa. 2006. 222f. Tese (Doutorado em Geografia) - Faculdade de Ciências e Tecnologia, Universidade Estadual Paulista, Presidente Prudente, 2006.

OLIVEIRA, Bianca Simoneli de. Ituiutaba (MG) na rede urbana tijucana: (re)configurações sócio- espaciais no período de 1950 a 2000. 2003. 204f. Dissertação (Mestrado em Geografia) - Instituto de Geografia, Universidade Federal de Uberlândia, Uberlândia, 2003.

OLIVEIRA, Hélio Carlos Miranda de. Urbanização e cidades: análises da microrregião de Ituiutaba (MG). 2013. 431f. Tese (Doutorado em Geografia) - Instituto de Geografia, Universidade Federal de Uberlândia, Uberlândia, 2013.

RODRIGUES, Arlete Moysés. Moradia nas cidades brasileiras. 10 ed. São Paulo: Contexto. 2003.

SANTOS, Milton. Metamorfoses do espaço habitado: fundamentos teóricos e metodológicos da Geografia. São Paulo: Hucitec, 1988.

SANTOS, Milton. Por uma Geografia nova: da crítica da Geografia a uma Geografia Crítica. São Paulo: EDUSP, 2002.

SILVA, Dalva Maria de Oliveira. Memória: lembrança e esquecimento. Trabalhadores nordestinos no Pontal do Triângulo Mineiro nas décadas de 1950 e 1960. 1997. 151f. Dissertação (Mestrado em História) - Pontifícia Universidade Católica, São Paulo, 1997.

SOARES, Beatriz Ribeiro. Habitação e produção do espaço em Uberlândia. 1988. 29of. Dissertação (Mestrado em Geografia Humana) - Departamento de Geografia, Universidade de São Paulo, São Paulo, 1988.

SOJA, Edward. Geografias pós-modernas. Rio de Janeiro: Zahar Editores, 1993.

SPOSITO, Maria Encarnação Beltão. Reestruturação urbana e segregação socioespacial no interior paulista. Scripta Nova, Barcelona, v. 11, $\mathrm{n}^{\mathrm{o}}$. 245, 2007. Disponível em: < http://www.ub.edu/geocrit/sn/sn-24511.htm>. Acessado em: 02/08/2012.

SPOSITO, Maria Encarnação Beltrão. Cidades médias: reestruturação das cidades e reestruturação urbana. In: (Org.). Cidades médias: espaços em transição. São Paulo: Expressão Popular, 2007a. p. 233-253. 
SPOSITO, Maria Encarnação Beltrão. O chão em pedaços: urbanização, economia e cidades do estado de São Paulo. 2004. 508f. Tese (Livre Docência em Geografia) - Faculdade de Ciências e Tecnologia, Universidade Estadual Paulista, Presidente Prudente, 2004.

Recebido em: 13/01/2020

Aprovado para publicação em: 20/07/2020 